Spring 2012

\title{
Principles for Drafting an Investment Policy With Illustrations
}

\author{
Robert Gyorgy
}

Anastasios G. Malliaris

Loyola University Chicago, tmallia@luc.edu

Follow this and additional works at: https://ecommons.luc.edu/business_facpubs

Part of the Business Commons

\section{Author Manuscript}

This is a pre-publication author manuscript of the final, published article.

\section{Recommended Citation}

Gyorgy, Robert and Malliaris, Anastasios G.. Principles for Drafting an Investment Policy With Illustrations. International Journal of Portfolio Analysis and Management, 1, 2: 144-160, 2012. Retrieved from Loyola eCommons, School of Business: Faculty Publications and Other Works, http://dx.doi.org/10.1504/

IJPAM.2012.049214

This Article is brought to you for free and open access by the Faculty Publications and Other Works by Department at Loyola eCommons. It has been accepted for inclusion in School of Business: Faculty Publications and Other Works by an authorized administrator of Loyola eCommons. For more information, please contact ecommons@luc.edu.

\section{(c) $($ () $\ominus$}

This work is licensed under a Creative Commons Attribution-Noncommercial-No Derivative Works 3.0 License. (C) Inderscience 2012 


\title{
PRINCIPLES FOR DRAFTING AN INVESTMENT POLICY \\ WITH ILLUSTRATIONS
}

\author{
Robert Gyorgy, CFA, CAIA \\ Northern Trust Global Investments \\ rg26@ntrs.com \\ and \\ Anastasios G. Malliaris, \\ Department of Economics and Finance \\ Loyola University Chicago \\ tmallia@luc.edu
}

\begin{abstract}
During the past few decades, significant theoretical advances in portfolio theory and asset pricing have substantially increased our understanding of how to construct optimal portfolios. These theoretical developments have challenged professional portfolio management to develop appropriate tools to incorporate these novel ideas. In this paper we contribute by focusing on the critical role of the investment policy as a tool that connects portfolio theory to portfolio management. We select, list, discuss and illustrate with examples several principles that are essential items of an investment policy.
\end{abstract}

Current version: FINAL May 15, 2012. This paper has been accepted for publication in the INTERNATIONAL JOURNAL OF POTFOLIO ANALYSIS AND MANAGEMENT.

JEL Classification: G10, G11, G15, G23

Keywords: Portfolio Selection, Strategic Allocation, Active vs Passive Portfolio Management, Investment Policy, Portfolio Management 


\section{PRINCIPLES FOR DRAFTING AN INVESTMENT POLICY \\ WITH ILLUSTRATIONS}

\section{Introduction}

In his panoramic overview of the history of risk, Peter Bernstein (1998) describes in detail the passionate pursuit of researchers to comprehend risk. Bernstein argues that our understanding of the concept of "risk" today is the result of a massive and encyclopedic intellectual effort that begins in ancient times and traces the history of philosophy, finance and mathematics from geometry to calculus to probability and eventually to modern stochastic calculus. Great thinkers such as Isaac Newton, Blaise Pascal, Pierre de Fermat, Jacob Bernoulli, Carl Friedrich Gauss, Louis Bachelier, John von Neumann and John Maynard Keynes, just to name a few, labored to put down the foundations of decision making under uncertainty. Yet, even Keynes was not able to simultaneously consider expected return and risk in this theory of investments. His celebrated marginal efficiency of investments introduced in Chapter 11 of Keynes (1936) essentially ranked potential investments in terms of only expected return, while uncertainty and risk were treated separately in his next famous Chapter 12.

It was Harry Markowitz $(1952,1959)$ who succeeded in constructing an integrated theoretical framework for both risk and return. Markowitz formulated the investor's problem as one that minimizes expected risks for a given expected return. Solving such a problem means that one searches for a portfolio with the lowest level of risk for a certain return. The novelty of the Markowitz formulation is the result that the riskiness of a portfolio depends on the covariance of its holdings instead of the riskiness of the individual holdings. In other words,

unlike Keynes (1936), return is not the sole determinant in investment decisions. If that were the 
case, there would be no argument for diversification, as investors would merely place all of their assets in securities with the highest expected return. Markowitz showed that a diversified portfolio reduces risk, and as a result, creates a more efficient portfolio.

The new paradigm proposed by Markowitz along with the pioneering work on capital asset pricing by William Sharpe $(1963,1964)$ proved to be a remarkably fertile methodology for investigating numerous aspects of portfolio selection. Recent books on portfolio management by Xidonas et al (2012) and asset pricing by Duffie (2001) and Cochrane (2005) document very thoroughly all the significant theoretical discoveries for the construction and management of portfolios. In addition the amazing accumulation of global wealth, currently valued at about $\$ 70$ trillion (for just equity and bonds and in the hundreds of trillions if derivative assets are included), is placing a formidable burden to quickly implement theoretical discoveries into principles of applied portfolio management.

It is the purpose of this paper to focus on the role of the Investment Policy as a guiding instrument connecting portfolio selection to portfolio management. Unless such an instrument is drafted, discussed, adopted and frequently revised, individuals, firms, investment committees and portfolio managers have no road map to execute their goals. In what follows we plan to select a few key components of an Investment Policy and illustrate their implementation in a real world case. The value of this paper comes from the use of actual data about the various asset classes during the period of 1997 to 2011. In addition to using actual market data that are publically available, this case also illustrates how actual data becomes a valuable input in forming future expectations and portfolio management recommendations. Furthermore, in this paper we demonstrate how the advice of the investment manager is reviewed, discussed, evaluated and finally implemented. These activities are performed by an Investment Committee 
that is directed by its Investment Policy. For reasons of confidentiality the authors will use a hypothetical name for the portfolio but all calculations are with real market data and the portfolio has been modified to make it more representative and thus more instructive.

\section{From Portfolio Theory to Portfolio Management}

Portfolio theory formulates the portfolio decision under uncertainty as a constrained maximization problem. It states the objective of maximizing returns subject to certain risks. Portfolio management identifies who is the maximizer, the amounts to be invested, the portfolio horizon, when new funds are to be added in the investment pool, when funds are to be withdrawn, and the long run objectives of such investments. Portfolio theory is mostly silent about these issues of portfolio management.

Consider an organization, such as a university, hospital, charitable institution, foundation or endowment, pension fund (with a defined benefit or a defined contribution plan), a life insurance company or a non-life insurance company, a bank or an individual. In our discussion and illustrations we will call this the REPRESENTATIVE ORGANIZATION (RO) and assume that it had accumulated by mid-1996 a certain amount, say $\$ 100$ million. The type of the organization, the investment period and the amount initially invested are not critical for the discussion and illustrations in this paper. If instead of an organization, we consider an individual; most of the analysis will still be useful with one major difference: individuals have relatively shorter investment horizons, usually a maximum of 30 to 40 years, while institutions have much longer horizons, perhaps several hundreds of years like Harvard and Yale. The implications of shorter horizons that apply to individuals are discussed in Malliaris and Malliaris (2008). 
We proceed with our analysis so that any organization or any individual reading this paper can find useful principles in applied portfolio management.

Prior to mid-1996, suppose that previous funds in excess of the organization's costs of operations were managed by an investment committee of 3 directors who had hired a portfolio management firm. The portfolio management firm presented quarterly reports, mostly over the phone. The 3 directors pursued an active investment policy and were very influenced by their own views and investments during this period of irrational exuberance as described by then Fed Chairman Greenspan. There was no explicit Investment Policy.

By mid-1996, new directors were added to the Board and it was decided to manage the endowment more comprehensively. With the help of legal and professional portfolio management advice, an Investment Committee was formed and several long meetings took place to draft an Investment Policy. As already mentioned, the purpose of this paper is to identify some of the major issues that need to be addressed by an investment policy document as a tool of portfolio management. In what follows we present and discuss the essential items of an Investment Policy, offering a narrative motivated by an RO but modified to remain relevant to a broader range of portfolios.

\section{Principles of Investment Policy}

The Investment Policy is the document that describes in detail all the major investment decisions that are necessary for managing the investment portfolio. Such decisions include: the objectives of the portfolio; the investment philosophy; asset allocation; benchmarking; execution; review, monitoring and feedback. Obviously numerous other issues are also essential and are discussed in the voluminous book of Maginn, Tuttle, Pinto, and McLeavey (2007). 
The objectives established by the RO included preservation of the purchasing power of the existing assets, provision for real long term growth and also requirements for liquidity as needed. These objectives were both long-term and short-term. Preserving the purchasing power of the existing assets indicates a minimal increase in the value of the assets that is at least equal to the rate of inflation. Achieving real long term growth describes a portfolio goal of growth over and above the rate of inflation. These two goals are critical for the financial success of the portfolio goals driven by the mission of the RO. The investment horizon is a very critical decision. For example an institution such as a University will have a very long investment horizon, perhaps an infinite horizon; however, an individual will have a much shorter horizon, say 30 years. Investment horizons need not be fixed, as in the case of individuals getting older with their investment horizons becoming shorter.

These goals were evaluated quarterly but in reality they were long term goals of both the Investment Committee of the $\mathrm{RO}$ and the managers hired to execute the decision of the Investment Committee. This Committee viewed the $\mathrm{RO}$ as an organization with a very long term investment horizon of several decades so quarterly fluctuations in the value of the portfolio did not trigger drastic changes in the portfolio management. The goal of making provisions for liquidity was a very short term goal. The Investment Committee acknowledged that if the RO unexpectedly experienced a financial shortfall from operations, or an unexpected and unbudgeted capital acquisition need emerged or an attractive real estate acquisition or remodeling arose, then with appropriate approvals assets of the portfolio could be sold to provide the necessary liquidity.

The investment philosophy describes how to achieve the stated objectives. At RO the investment philosophy emphasized a conservative, disciplined, consistent and diversified approach. Conservative meant that the Investment Committee took seriously its fiduciary 
responsibility to pursue relatively low risk investment strategies. A conservative approach does not mean a strategy that attempts to completely eliminate risk but rather one that weighs carefully the incremental increase in return to be expected due to assuming a higher risk. Given the emphasis placed on reducing the total risk of the portfolio, there has also been much research on the topic of risk adjusted performance. Over the years there have been many different ratios proposed as a possible measurement for risk adjusted return. The Sharpe ratio was introduced in William Sharpe (1966) as a means of comparing portfolios with different levels of risk. The ratio proposed involved finding the difference in return between the fund examined and a benchmark asset, usually the risk free rate of return. The difference in return is divided by the variance of the fund examined. The Investment Committee at RO has used the Sharpe ratio as an important tool, other than the total return of a portfolio, in both evaluating existing portfolio managers and in selecting new ones.

Disciplined meant that both the Investment Committee and the portfolio managers chosen followed careful financial analysis with detailed data using principles of sound portfolio analysis. A consistent investment policy is one that remains stable over time so investment results can be analyzed and sound comparisons can be made. Changing an investment philosophy every couple of years reduces the validity of portfolio evaluations and diminishes the statistical power of comparisons. Finally, an investment philosophy must embrace the concept of diversification since this is one of the fundamental principles of modern portfolio theory.

Asset Allocation is another important component to modern portfolio theory and its role is fundamental in the creation of an optimal portfolio. Numerous studies on the determinants of portfolio performance have shown that asset allocation has a highly explanatory role on the volatility of a portfolio. Recent literature has also confirmed this result. Bekkers, Doeswijk, and 
Lam (2009) demonstrate that there is a significant benefit to portfolio performance by allocating portfolio assets across a variety of asset classes.

Asset Allocation is the direct consequence of portfolio theory. Recall that portfolio theory as initially formulated by Markowitz $(1952,1959)$ and reformulated in Constantinides and Malliaris (1995) begins with a set of assets, information about the covariance matrix of these assets and solves for the weights of these assets in such a way that the risk of the portfolio is minimized for a chosen return. While in portfolio theory we represent the set of assets as a vector of an arbitrary order in the actual portfolio management process, the Investment Committee needs to select the assets that will be included in the portfolio. After such a selection has been made the portfolio problem will identify several weights for the assets chosen, the corresponding expected return and the minimized risk. Thus, Asset Allocation is the direct application of portfolio theory applied to a certain group of assets or asset classes. An Asset Allocation that selects certain asset classes, forms returns objectives for the Investment Committee, identifies risk tolerance, along with capital markets expectations over the long-run, say a 10-year investment horizon is called Strategic Asset Allocation. Making short-term adjustments to the weights of the investment classes and/or allowing for short-term deviations from the strategic asset allocation targets to respond to expected relative performance among the chosen asset classes is called Tactical Strategic Allocation. Table 1 gives an illustration of these two concepts. In this table we use 5 investment classes and specify the chosen strategic allocation; tactical allocation is expressed as a range from a low to a high percentage that obviously includes the percent of strategic allocation; if a tactical allocation range is not specified then the investment manager is responsible for adjusting the portfolio allocation continuously. For any 
given moment in time there is an actual allocation that may deviate from the strategic allocation but which ought to satisfy the individual ranges of allocation per investment class.

Table 1: Asset Class Allocations

\begin{tabular}{lccc} 
Asset Class & $\begin{array}{c}\text { Strategic } \\
\text { Allocation }\end{array}$ & $\begin{array}{c}\text { Tactical } \\
\text { Range }\end{array}$ & Benchmark \\
\hline US Equity & $45 \%$ & $40 \%-50 \%$ & Russell 3000 \\
$\begin{array}{l}\text { International } \\
\text { equity }\end{array}$ & $15 \%$ & $10 \%-25 \%$ & MSCI EAFE
\end{tabular}

$\begin{array}{lccc}\text { Fixed income } & 35 \% & 30-40 \% & \begin{array}{c}\text { Barclays Aggregate } \\ \text { Bond Index }\end{array} \\ \text { High Yield Bonds } & 5 \% & 0-10 \% & \begin{array}{c}\text { Bank of America } \\ \text { Merrill Lynch High } \\ \text { Yield Index }\end{array} \\ \text { Cash Equivalents } & 0 \% & 0-100 \% & \begin{array}{c}\text { 90-Day Treasury } \\ \text { Bills }\end{array}\end{array}$

Once a strategic allocation is selected, the Investment Policy proceeds to propose appropriate benchmarking for each asset class. Actually the various simulations performed by the portfolio management team and selected by the Investment Committee use the historical risk and return data of these benchmarks to formulate alternative scenarios of expected risk and return for the chosen classes. Table 1 also identifies the chosen benchmarks for the selected asset classes. 
At this point, the Investment Committee will be most likely prepared to authorize the chosen investment manager to proceed with the execution of investing the available funds. There are two options: to invest all or a portion of the available funds in either a mutual fund or an exchange traded fund directly in the chosen benchmark. This is known as passive management of the portfolio and it is one that has the lowest management fees; however, the investment manager may propose and the Investment Committee, after careful considerations, may agree to follow an active management of all or a portion of the portfolio. Investment managers have sophisticated procedures that allow them to select few managers who have a proven record of out-performing specific benchmarks. In our section below we describe the methods used by the investment manager during the 1996 to 2011 period and the actual returns of active vs. passive investment management.

Once the Investment Committee has chosen what asset classes will be invested passively in the selected benchmark and what classes will be actively managed and by whom, the investment manager executes these decisions and continuously monitors the invested funds. If the investment manager observes market conditions that justify major concerns or if certain active managers experience major staff changes, then the Chief Financial Officer of the RO is immediately notified who in turn notifies members of the investment committee to evaluate current conditions and, if need be, to make appropriate decisions. However, if the economy, financial markets and the involved portfolio managers all perform normally, then an official review will take place quarterly. This is a formal review with a detailed report prepared by the portfolio manager that includes an analysis of the economy, an analysis of the markets in general, the performance of the overall portfolio, the performance of each asset class relative to its benchmark and the performance of each active manager relative to the chosen benchmark. 
During such review meetings, the Investment Committee offers its feedback on the presentation made and evaluates the performance of the investment manager who sends one or two professionals to make their review, propose changes, suggest certain issues for consideration and express their professional judgment of potential future economic scenarios with their impact in terms of both risk and return of the portfolio. In these quarterly meetings, the issue of portfolio rebalancing arises.

The rebalancing of the portfolio is also an important concept of modern portfolio theory. It is highly related to asset allocation in that while asset allocation should reduce the volatility of a portfolio, not all assets will have the same return, and will result in a new distribution of portfolio assets over time. In order to bring the portfolio back to its original construction of the chosen strategic asset allocation, rebalancing is a necessary procedure. Recent literature on the topic, such as Brown, Ozik, Scholz, (2007) indicates that, under certain conditions, the use of derivatives is a cost effective manner in which to alter the asset allocation of a portfolio. That is, it can be cheaper, through fewer transaction costs, than simply buying and selling more of each asset to rebalance the portfolio. Large organizations tend to hire an overlay manager who in a separate account manages a futures portfolio which is used to rebalance the portfolio to the strategic asset allocation.

Perold and Sharpe (1995) examined four different rebalancing strategies - buy and hold, constant mix, constant proportion portfolio insurance and option based portfolio insurance. Most institutional portfolio managers use the constant mix strategy. 


\section{The Process of Asset Allocation}

The portfolio manager (Northern Trust) provided a Strategic Planning Report to the Investment Committee every 3-5 years with the goal of evaluating the current asset allocation relative to similar organizations, to establish the range of asset classes included in the asset allocation modeling, to examine the potential risk adjusted returns available for different asset mixes and to update the investment policy statement. The Strategic Planning report included (1) Average asset class allocation following National Association of College and University Business Officers (NABUCO) and Northern Trust Universes (2) Asset class risk, return and correlation assumptions and (3) an efficient frontier of various mixes using the asset classes of Table 1. Allocation ranges were established for each individual asset class included in the asset allocation modeling.

During the strategic planning discussions the merits of other asset classes (real estate, private equity, and hedge funds) were discussed as well.

Table 2 shows the asset class risk and return assumptions of the allocation model, and Table 3 shows the asset correlations used in the model:

Table 2: Asset Class Risk and Return Assumptions

\begin{tabular}{lrrrr}
\multicolumn{1}{c}{ Asset Class } & & Return & & \multicolumn{1}{c}{ Risk } \\
\cline { 1 - 1 } U.S. Equity & & $10.50 \%$ & & $16.50 \%$ \\
International equity & $12.00 \%$ & & $18.00 \%$ \\
Core Fixed Income & $5.60 \%$ & & $8.00 \%$ \\
High Yield & $9.00 \%$ & & $7.75 \%$
\end{tabular}


Table 3: Asset Class Correlations

$\begin{array}{lllll}\text { Asset Class } & (1) & (2) & (3) & (4) \\ \text { (1) U.S. Equity } & 1.00 & 0.46 & 0.26 & 0.48 \\ \text { (2) International Equity } & 0.46 & 1.00 & 0.17 & 0.26 \\ \text { (3) Core Fixed Income } & 0.26 & 0.17 & 1.00 & 0.40 \\ \text { (4) High Yield } & 0.48 & 0.26 & 0.40 & 1.00\end{array}$

These risk, return and correlation assumptions are forward looking capital market assumptions. Beyond the traditional political, economic and financial markets inputs, "building block" assumptions were used to generate the long term total return forecast for the individual asset classes. These "building blocks" include productivity and labor force growth, government bond term premium, corporate bond credit premium, high yield bond risk premium, equity risk premium and valuation changes. Risk and correlation assumptions are mainly driven by long term (20 years) of historical data. Data in Tables 2, 3 and 4 are expectations as of early 2000.

Table 4 shows the asset mixes considered and Figure 1 plots the efficient frontier:

Table 4: Asset Allocation and Performance

\begin{tabular}{|c|c|c|c|c|c|}
\hline Asset Class & Mix 1 & Mix 2 & Mix 3 & Mix 4 & Mix 5 \\
\hline U.S. Equity & $40.00 \%$ & $40.00 \%$ & $45.00 \%$ & $50.00 \%$ & $55.00 \%$ \\
\hline International Equity & $5.00 \%$ & $15.00 \%$ & $15.00 \%$ & $15.00 \%$ & $15.00 \%$ \\
\hline Core fixed Income & $50.00 \%$ & $40.00 \%$ & $35.00 \%$ & $30.00 \%$ & $25.00 \%$ \\
\hline High Yield & $5.00 \%$ & $5.00 \%$ & $5.00 \%$ & $5.00 \%$ & $5.00 \%$ \\
\hline Return & $8.05 \%$ & $8.69 \%$ & $8.94 \%$ & $9.18 \%$ & $9.43 \%$ \\
\hline Std Deviation & $9.21 \%$ & $9.77 \%$ & $10.32 \%$ & $10.89 \%$ & $11.50 \%$ \\
\hline Sharpe ratio & 0.60 & 0.63 & 0.62 & 0.61 & 0.60 \\
\hline
\end{tabular}


Figure 1: The Efficient Frontier for Current Set of Mixes

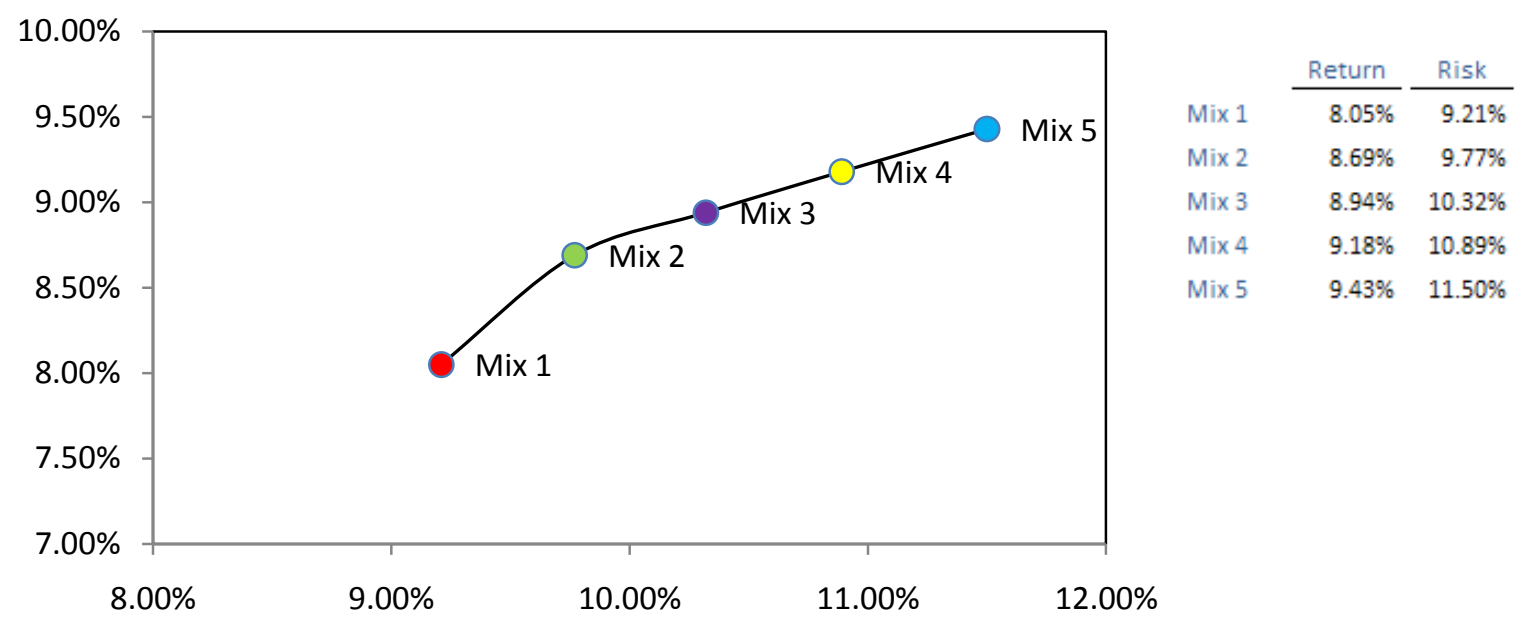

The efficient frontier was developed using mean variance analysis developed by Markowitz. Originally Markowitz developed the mean-variance analysis in the context of selecting a portfolio of common stocks. Over the past decades, mean variance has been increasingly applied to asset allocation. Practitioners using the Markowitz model use linear constraints for the individual asset classes to incorporate the investor's limitations.

The Black-Litterman model and resampled mean variance optimization are two new techniques that are also used by practitioners to develop well-diversified asset allocations.

After reviewing the individual asset mixes the Investment Committee chose Mix 3 which had an expected return of $8.94 \%$ and an expected risk of $10.32 \%$.

Five years later a Strategic Planning Report was developed again by the investment manager to help the Investment Committee to re-evaluate its strategic asset allocation. Tables 5 and 6 show the asset class risk, return and correlation assumptions used in the 2006 asset allocation modeling: 
Table 5: 2006 Asset Class Return Assumptions

\begin{tabular}{lrrrr}
\multicolumn{1}{c}{ Asset Class } & & Return & & \multicolumn{1}{c}{ Risk } \\
\cline { 1 - 1 } U.S. Equity & & $8.30 \%$ & & $15.00 \%$ \\
International Equity & $8.50 \%$ & & $17.00 \%$ \\
Core Fixed Income & & $5.00 \%$ & & $7.50 \%$ \\
High Yield & $7.00 \%$ & & $10.00 \%$
\end{tabular}

Table 6: 2006 Asset Class Correlations

Asset Class

(1) U.S. Equity

(2) International Equity

(3) Core Fixed Income

(4) High Yield
(1)

1.00

0.89

$-0.39$

0.43
(2)

0.89

1.00

$-0.40$

0.40
(3)

$-0.39$

(4)

0.43

$-0.40 \quad 0.40$

$1.00-0.08$

$-0.08 \quad 1.00$

Table 7 shows the asset mixes considered and the efficient frontier is plotted in Figure 2:

Table 7: 2006 Asset Allocation and Performance

\begin{tabular}{|c|c|c|c|c|c|}
\hline Asset Class & Mix 1 & Mix 2 & Mix 3 & Mix 4 & Mix 5 \\
\hline U.S. Equity & $40.00 \%$ & $40.00 \%$ & $45.00 \%$ & $50.00 \%$ & $55.00 \%$ \\
\hline International Equity & $5.00 \%$ & $12.00 \%$ & $15.00 \%$ & $15.00 \%$ & $25.00 \%$ \\
\hline Core Fixed Income & $53.00 \%$ & $43.00 \%$ & $35.00 \%$ & $30.00 \%$ & $25.00 \%$ \\
\hline High Yield & $2.00 \%$ & $5.00 \%$ & $5.00 \%$ & $5.00 \%$ & $5.00 \%$ \\
\hline Return & $6.53 \%$ & $6.84 \%$ & $7.11 \%$ & $7.28 \%$ & $7.44 \%$ \\
\hline Std Deviation & $6.43 \%$ & $7.44 \%$ & $8.62 \%$ & $9.40 \%$ & $10.21 \%$ \\
\hline Sharpe Ratio & 0.63 & 0.58 & 0.53 & 0.51 & 0.48 \\
\hline
\end{tabular}


Figure 2: 2006 Efficient Frontier

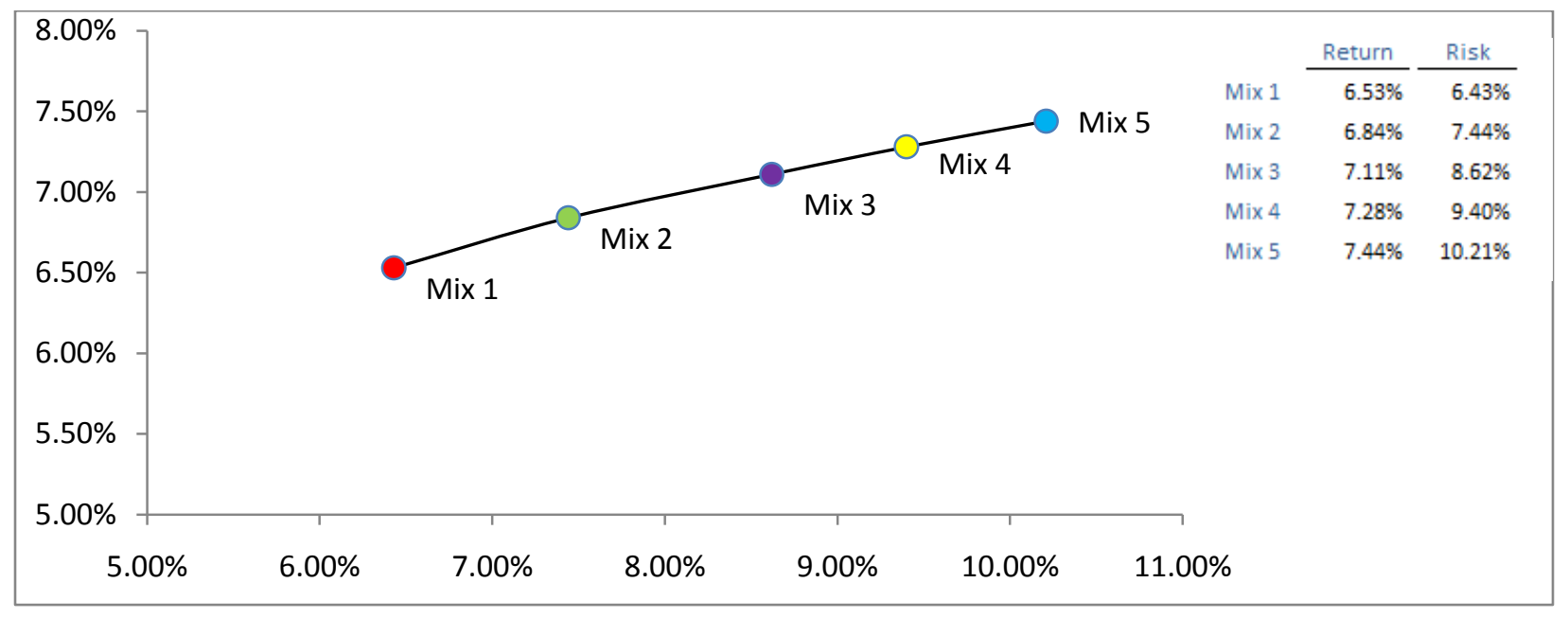

The Investment Committee also reviewed the average allocations provided by the NABUCO Endowment Study (2005) on Table 8.

Table 8: Funds Assets in Millions

\begin{tabular}{|c|c|c|c|c|c|}
\hline Asset Class & $\leq \$ 25 \mathrm{~m}$ & $\$ 25-\$ 50$ & $\underline{50-100}$ & $\underline{100-500}$ & 500-1bn. \\
\hline U.S. equity & $60.7 \%$ & $61.2 \%$ & $60.6 \%$ & $57.8 \%$ & $57.3 \%$ \\
\hline Fixed Income & 27.8 & 23.3 & 22.1 & 18.9 & 16.0 \\
\hline Real Estate & 1.7 & 3.8 & 3.2 & 3.0 & 3.7 \\
\hline Cash & 6.1 & 3.3 & 3.8 & 2.5 & 1.7 \\
\hline Hedge & 2.4 & 5.8 & 7.0 & 11.4 & 15.8 \\
\hline Private Equity & 0.2 & 0.3 & 0.7 & 2.2 & 4.7 \\
\hline Venture Cap & 0.0 & 0.3 & 0.4 & 1.1 & 2.0 \\
\hline Other & 1.1 & 2.1 & 2.1 & 3.0 & 2.3 \\
\hline
\end{tabular}


Table 8 shows the average asset class allocation during 2005 for 738 institutions surveyed by NABUCO. The Northern Trust Universe information was considered as well. Table 9 shows the allocation ranges for 71 institutions custodied at Northern Trust:

Table 9

Northern Trust Foundations \& Endowments Universe as of 9/30/05 (71 Funds)

$\begin{array}{lrrrrrr} & \text { US Equities } & \text { Intl Equities } & \text { Private Equity } & \text { Real Estate } & \text { Fixed Income } & \text { Cash } \\ \text { 25th Pct. } & 58 \% & 16 \% & 12 \% & 0 \% & 36 \% & 5 \% \\ \text { Median } & 46 \% & 11 \% & 4 \% & 0 \% & 30 \% & 3 \% \\ \text { 75th Pct. } & 35 \% & 4 \% & 0 \% & 0 \% & 23 \% & 2 \%\end{array}$

\section{Active vs. Passive Management}

The portfolio manager has the ultimate responsibility for the implementation of the strategic asset allocation for the $\mathrm{RO}$ through the use of active and passive investment managers. The performance of each manager is monitored by the portfolio manager as part of the continuing governance process.

The case for passive funds is articulated by Jack Bogle (1999) in his book. The main benefits of passive management are the lower fees, lower turnover and the ease to control total portfolio risk. On the other hand passive funds are less attractive in less efficient markets, are more exposed on the downside and can have higher concentration of risk during market peaks.

The evaluation of active investment managers starts with a universe of managers which fit specific criteria and focuses on four key areas: people, investment philosophy and process, 
business model and performance. The team has to have proven experience and demonstrated pedigree in the strategy they follow over time and has to have a clear philosophy and a disciplined process. A quantitative and qualitative analysis of the historical performance is performed to evaluate the persistency and repeatability of performance. Compliance and operational due diligence are also key components of the investment evaluation process.

In many cases multiple investment managers are employed in an asset class. Potential combinations of successful managers are evaluated based on qualitative understanding of how they will complement one another over the course of a market cycle. Quantitative testing and analysis of these combinations is performed using both returns-based and holdings based analysis. A disciplined rebalancing process among the managers is employed to maintain the desired characteristics over time. These functions are performed by the investment manager who reports to the Investment Committee on a regular basis the selection of the best managers to perform their active management of funds invested with them.

\section{Quarterly reviews}

The quarterly reviews have two main components: market review and performance review. The market review includes the review of the state of the economy, performance of difference asset classes and sectors. The performance review includes a presentation of the returns for the individual managers, asset classes and portfolio as a whole. Performance is always compared to a predetermined benchmark. Both gross and net of fees performance is evaluated. Figure 3 shows the growth of a dollar measured as gross and net of fees during the most recent decade. Calculations can easily be performed for longer periods of time. 
Figure 3: Growth of One Dollar Net Over 10 Years Net of Fees

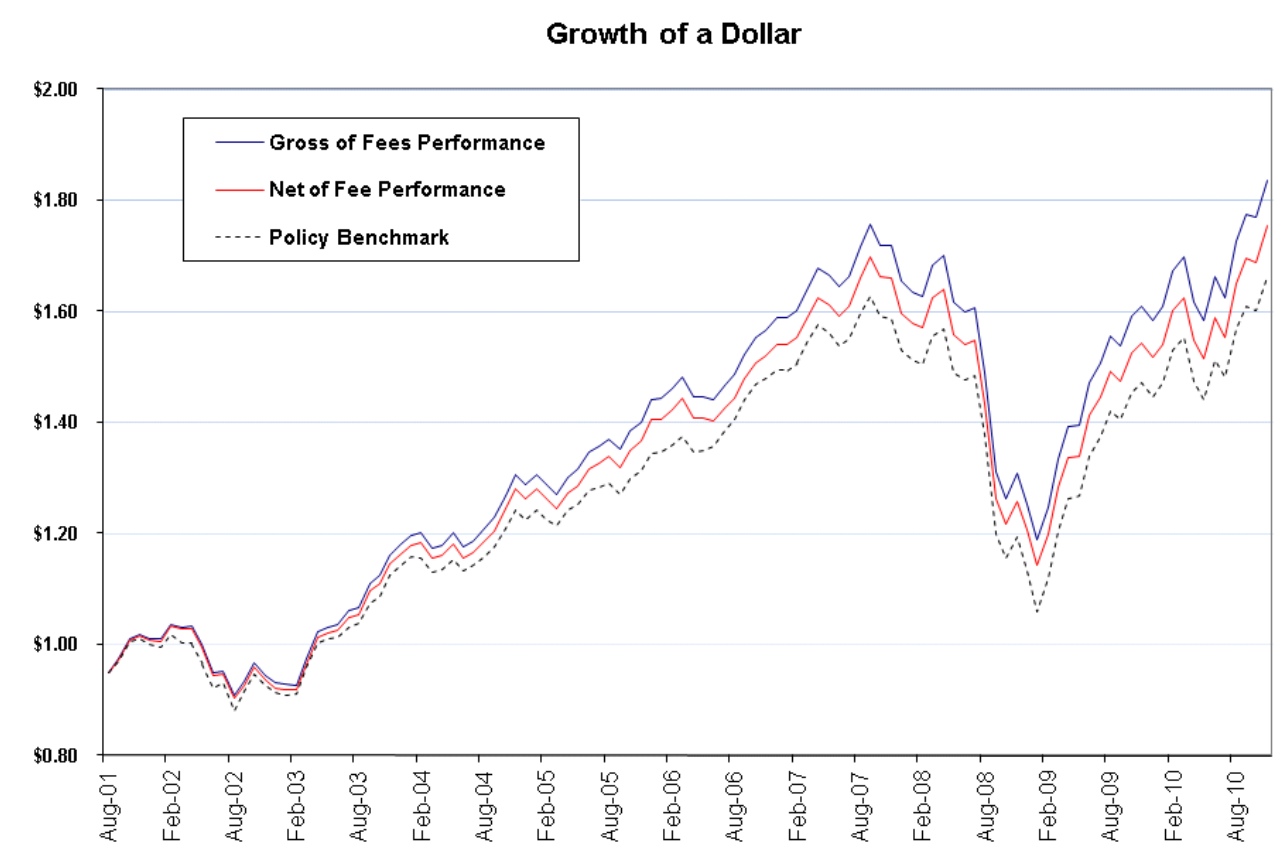

The outperformance over the time period was driven by strong investment manager selection and a disciplined portfolio construction process. The fees depend on the size of the account, the asset allocation and the active-passive mix in the portfolio.

During exceptional time periods (like the credit crisis) the Investment Committee might suspend the rebalancing between asset classes for a time period if it feels that the markets are irrational and/or illiquid. This was actually proposed by the Investment Committee during the period of October 1, 2008 to June 2009. The major financial turmoil during this period was evaluated during the regular quarterly meeting in October, January, April and early July. Rebalancing was suspended during this period since the value of the class of fixed assets was increasing while stocks were declining. Thus, it did not make sense selling bonds and buying stocks to preserve the strategic long-term allocation. Quickly, when the market recovered, the rebalancing was reintroduced. 


\section{Concluding remarks}

Minutes of the regular quarterly meetings during the past 15 years provide a wealth of information about the actual management of the portfolio of the RO. A sample of such information has been presented above. The emphasis is on the formulation of a detailed Investment Policy that is reviewed frequently and modified to include newer developments in portfolio management. While new asset classes are often added, others deleted, the asset allocation of essentially $60 \%$ equity and $40 \%$ fixed has remained throughout the period of 19972011. During this period the range of active to passive portfolio management fluctuated from about $80 \%$ actively managed to about $40 \%$ actively managed. Decisions to change the mix of active to passive were made by the Investment Committee on the basis of portfolio performance and cost of fees. Northern Trust always provided expert advice on the issue of chosen and dismissed portfolio managers.

In conclusion, the drafting, frequent revision and the guidance provided by an Investment Policy are most valuable for the actual management of portfolios, independent of their size, complexity and ownership. Such a policy highlights all the important aspects of the process of managing funds and it also incorporates the newest theoretical innovations in portfolio theory. A generic sample of such a policy is provided in the Appendix below. Investment and Finance Committees can begin with such an Investment Policy and modify it to reflect the specific goals, strategies and policies they wish to follow. The final document may also be reviewed by a legal counsel and approved by the Board of Directors. 


\section{Appendix}

Sample Investment Policy Statement prepared by the Northern Trust.

It is the policy of the organization to invest funds in excess of its current daily requirements in investments and securities that may be comprised of cash and equivalents, fixed income securities, equity securities, and alternative investment strategies. Any allocation to any of these investments will be commensurate with the time horizon in which the organization expects the funds to be used.

\section{OBJECTIVES}

The objectives of the investment program are to:

1. Preserve the purchasing power of the existing assets,

2. Provide for real long term growth of the asset pool,

3. Provide liquidity as needed.

The purpose of this document is to establish policy and guidelines which will provide for the maintenance and enhancement of the invested assets of the organization. This document will be reviewed at least annually by the Finance Investment Committee ("the Committee") of the organization's Board of Directors ("Board") and updated or modified as needed to reflect changes in both the financial markets and needs of the organization. By acceptance of this policy by the Board, all previously approved policies and guidelines relating to management of the organization's funds are superseded. Any revisions to this policy, unless otherwise delegated to the Finance Committee by the Board, shall require approval by the Board.

\section{INVESTMENT PHILOSOPHY}

The organization's assets exist to provide long term support to the mission of the organization, while striking a balance between the immediate budgetary requirements, fund raising potential and its expected capital requirements. Accordingly, the investment philosophy of the organization is based on a disciplined, consistent, and diversified approach utilizing multiple asset classes and multiple managers. The organization adheres to the principle that assuming incremental degrees of investment risk is generally rewarded with compensating returns over time. It is not a breach of fiduciary responsibility to pursue relatively higher risk investment strategies, subject to the guidelines in this policy. The intent is to accommodate styles and strategies considered reasonable and prudent.

The organization's mission may necessitate distributing a portion of the investment return from time to time. Over the long term, the investment return is expected to be greater than the amount 
distributed and this excess return will be reinvested. The reinvested portion should be sufficient to cover expected future inflation and investment management and related fees so that the real value of the Organization's assets is preserved and maintained over time.

The management of the funds may be assigned to one or more professional investment managers. Any funds not assigned to an investment manager shall be managed by the appropriate Organization officers and the Finance Committee. Several Investment managers shall be selected from established and financially sound organizations which have a proven and demonstrated track record managing similar funds. Selection of investment managers shall depend upon factors established by the Finance Committee and will be consistent with applicable state laws.

Assets may be invested in one or more diversified commingled funds. Assets will typically be diversified among high quality stocks and bonds. Additional asset classes may be included when it is reasonable to expect the additional asset class will either increase return or reduce risk, or both.

\section{RESPONSIBILTIES}

Investment Committee of the Board: Provides direction for the investment of the financial assets of the organization. The Finance Committee is charged with the responsibility to establish and maintain policies and guidelines for the receiving and investment of the Organization's assets.

Vice President of Finance: Implements, or causes to be implemented, investment policies and is responsible for all transactions.

Investment Manager: Manages portfolio within investment guidelines stipulated by this policy, and in accordance with the terms of the specific trust agreement between the Organization and the manager.

\section{STANDARD OF CARE}

All persons involved in the management of the invested funds shall use the care, skill, prudence and diligence under the circumstances then prevailing that a prudent person acting in a like capacity and familiar with such matters would use in the conduct of an enterprise of a like character and with like aims.

\section{STRATEGY}

Investment Vehicles

The organization's assets will be invested in portfolios of equities, fixed income and other assets as designated by the finance committee. The fund will be broadly diversified through investment in multiple markets and use of multiple investment styles. The purpose of diversifying among multiple markets and multiple investment styles is to enhance real returns while reducing 
volatility. In addition, diversification will provide assurance that no single security or class of securities will have a disproportionate impact on the fund's aggregate results.

Commingled Funds

Commingled Funds, Registered Mutual Funds or Exchange-Traded Funds may be used in any category. When one is selected, however, it is expected that the fund will comply with its most recent prospectus which has been reviewed and found acceptable by the Committee.

Asset Allocation and Investment Guidelines

The organization's assets will be invested according to the asset allocation targets shown on Attachment 1 at the end of this document. These targets may be modified from time to time by the Finance Committee. Guidelines for investment portfolios are set forth below:

\section{Short Term Investments}

Cash balances and all funds necessary to meet the organization's liquidity requirements shall be invested in a short term investment portfolio or commingled money market fund. The primary objective of the short term fund is to earn a rate of return comparable to that of a Tier 1 money market fund.

\section{Equity Investments}

Investments in one or more diversified commingled actively or passively managed funds is appropriate and necessary to create a well-diversified portfolio, incorporating multiple asset classes and investment styles. The investment manager, subject to the guidelines as the Finance Committee may adopt from time to time, shall have complete discretion to manage the assets in each portfolio to best achieve the investment objectives. Other guidelines adopted by the Finance Committee, such as dealing with social responsibility issues, will be furnished to the managers as appropriate.

Fixed Income Investments

Investments in one or more diversified commingled actively or passively managed funds is appropriate and necessary to create a well-diversified portfolio, incorporating multiple asset classes and investment styles. Derivative securities shall not be used to increase the actual or potential risk posture of the portfolio. Investment managers using derivative securities may not affect a leveraged portfolio structure, i.e., options and futures positions must be offset in their entirety by corresponding cash and securities.

Alternative Investments 
In order to enhance portfolio results, the Organization's assets may be invested in alternative asset classes as approved by the Finance Committee. These investments are intended to raise portfolio returns and/or lower total portfolio volatility. In most, but not all cases, these investments will be implemented via a diversified "fund of funds" vehicle. Therefore, investment restrictions are established by the offering documents for each fund. Alternative investments may include, but are not limited to, Private Equity, Hedge Funds, Real Estate, Timber Funds, and Commodities Funds.

\section{PERFORMANCE MEASUREMENT}

The Finance Committee will establish specific performance objectives and provide for monitoring the investment performance of the managers employed to manage the Organization's assets. On a quarterly basis, the Finance Committee will review each manager's investment performance relative to the performance objective, risk guidelines, the manager's stated investment philosophy, and the manager's peer group. For purposes of reviewing performance, it is intended that the following objectives indicated earlier be achieved over a 5-year moving period, net of investment management fees.

The performance review at the total portfolio level will evaluate total program performance versus the overall policy benchmark. The performance review at the asset class level will evaluate asset class performance versus the benchmark. The performance review at the manager level will evaluate manager performance versus appropriate investment style benchmarks and stated investment approaches.

Total Fund

The total return objective for the organization's fund, measured over full market cycles, shall be to meet or exceed the weighted policy benchmark as designated by the Finance Committee and place in the top $1 / 3$ of a universe of balanced funds of a publicly-recognized performance measurement service, as selected by the Committee, for any five-year period.

Equity Investments

The total return for each "active" equity investment manager is expected to exceed by not less than 100 basis points $(1.0 \%)$ the relevant equity benchmark. The total return for an index fund is expected to match, but not fall below, the relevant equity benchmark over any 5-year period.

The total return of the actively managed developed countries international equities should exceed by not less than 100 basis points (1.0\%) per annum the performance of the MSCI EAFE Index over any 5- year period. 
The total return of the emerging market equities fund should exceed the return of the MSCI Emerging Markets Index by 100 basis points (1.0\%) over any 5-year period.

Fixed Income Investments

The total return for the Pooled Fixed Income Fund and any fixed income investment manager is expected to exceed by 50 basis points $(0.50 \%)$ the Barclays Aggregate Bond Index, or another benchmark as designated by the Finance Committee. The total return for an index fund is expected to match, but not fall below, the relevant equity benchmark during any 5-year period.

High Yield Fixed Income

To exceed by not less than 50 basis points (1/2\%) the performance of the Bank of America Merrill Lynch High Yield Index with the high yield (below investment grade) fixed income portion of the funds during any 5 year period.

Alternative Investments

Alternative investment shall be measured against appropriate benchmarks for each strategy as established by the committee.

\section{FEES AND EXPENSES}

Investment manager fees and other investment expenses shall be reviewed annually by the Finance Committee. Investment contracts will be reviewed annually by the Finance Committee.

\section{CONFLICT OF INTEREST}

No investment shall knowingly be made in which any officer or director of the Board or any member of the Committee has a controlling financial interest.

\section{APPLICATION OF INVESTMENT POLICIES}

It is the expectation of the Organization that these Investment Policies shall be applied in conducting the investment affairs of the Seminary. The investment policies will be communicated to each investment manager and their expression of concurrence will be part of the annual review. 
Attachment 1

ASSET ALLOCATION GUIDELINES

Assets Class $\quad$ Strategic Benchmark

U.S Equity $\quad 45.0 \% \quad$ Russell 3000 Index

International Equity $\quad 15.0 \% \quad$ MSCI ACWI Ex-Us Index

Emerging Market Equities $\quad 0.0 \% \quad$ MSCI Emerging Markets Index

Fixed Income $\quad 35.0 \% \quad$ Barclays Aggregate Bond Index

High Yield Bonds $\quad 5.0 \% \quad$ Bank of America ML High Yield Index

Cash Equivalents * $\quad 0.0 \% \quad 90$-Day Treasury Bills

*Cash balances may be maintained to meet anticipated liquidity needs

References

Bekkers, Niels, Doeswijk, Ronald Q. and Lam, Trevin W. (2009), "Strategic Asset Allocation: Determining the Optimal Portfolio with Ten Asset Classes." Journal of Wealth Management, Vol. 12 No. 3, pp. 61-77.

Bernstein, Peter (1998), Against the Gods, the Remarkable Story of Risk. Hoboken: Wiley

Bogle, John (1999), Common Sense on Mutual Funds: New Imperatives for the Intelligent Investor. New York: John Wiley \& Sons. 
Brown, David, Ozik, Gideon, Scholz, Daniel (2007), "Rebalancing Revisited: The Role of Derivatives,” Financial Analysts Journal, Vol. 63 No. 5, pp. 32-44.

Cochrane, John H. (2005), Asset Pricing. Princeton: Princeton University Press.

Constantinides, G.M. and Malliaris, A. G. (1995) "Portfolio Theory," Finance, Handbooks in Operations Research and Management Science, Vol. 9 ed. R.A. Jarrow, V. Maksimovic and W.T. Ziemba, Amsterdam: Elsevier, pp 1-30.

Duffie, Darrell (2001), Dynamic Asset Pricing Theory. Princeton: Princeton University Press.

Keynes, John M. (1936), The General Theory of Employment, Interest and Money. New York: Harcourt, Brace \& World.

Maginn, John L., Donald L. Tuttle, Jerald E. Pinto, Dennis W. McLeavey (2007), Managing Investment Portfolios. Hoboken: Wiley.

Malliaris, A. G. and Mary Malliaris (2008), "Investment Principles for Individual Retirement Accounts", Journal of Banking and Finance, Vol. 32 No. 3, pp. 393-404.

Markowitz, Harry (1952), "Portfolio Selection.” The Journal of Finance, Vol. 7 No. 1, pp. 77-91.

Markowitz, Harry (1959), Portfolio Selection: Efficient Diversification of Investments. Hoboken: Wiley.

Perold, Andre F., Sharpe, William F. (1995) "Dynamic Strategies for Asset Allocation” Financial Analysts Journal / Vol. 51 No. 1,January-February 1995.

Sharpe, William F. (1963). "A Simplified Model for Portfolio Analysis". Management Science vol. 9 No. 2, pp. 277-93.

Sharpe, William F. (1964). "Capital Asset Prices - A Theory of Market Equilibrium Under Conditions of Risk". Journal of Finance Vol. 19 No. 3, pp. 425-42.

Sharpe, William F. (1966), "Mutual Fund Performance." Journal of Business, Vol. 39 No. 1, pp. 119-138.

Xidonas, Panos, George Mavrotas, Theodore Krintas, John Psarras, Constantin Zopoundis (2012), Multicriteria Portfolio Management. New York:Springer 